\title{
Developing Cultural Humility During Short-Term Study Abroad Immersion
}

\author{
Katheryn R. Fernandez ${ }^{1}$ \\ ${ }^{1}$ School of Nursing, Capital University, Bexley, Ohio, USA \\ Correspondence: Katheryn R. Fernandez, School of Nursing, Capital University, 323 Battelle Hall, Bexley, OH \\ 43209, USA. Tel: 1-614-236-7232.
}

Received: July 7, 2020

Accepted: August 13, 2020

Online Published: August 20, 2020

doi:10.20849/ijsn.v5i3.764

URL: https://doi.org/10.20849/ijsn.v5i3.764

\begin{abstract}
Background: Cultural humility is an essential part of nursing education and practice today. We often teach cultural competence but do not take it further to develop the cultural humility needed for an understanding of being and becoming in today's global environment. Method: This article describes a ten-day immersive study abroad experience to Mexico using strategies to develop cultural humility. Cultural immersion is a high impact practice and was used along with reflective writing and debriefing. Results: Cultural humility did emerge because of the trip to Mexico. Strategies used to develop this were reflective writings, discussions, debriefing and cultural immersion. These emerged as strong strategies to use in study abroad experiences. Conclusion: Nursing students can develop cultural humility during short-term immersion trips to Mexico. Further study of these strategies are needed to develop further knowledge of cultural humility and its impact on developing culturally congruent health care, reducing health disparities and promoting health equity.
\end{abstract}

Keywords: cultural humility, nursing students, short-term study abroad, high impact practices

\section{Background}

Experiencing short-term immersion study abroad can increase undergraduate nursing students' cultural competency through the process of internalizing the practice of cultural humility. According to Bond, Kardong-Edgren and Jones (2001), pre-licensure nursing students, practicing registered nurses and advanced practice nurses overall in the United States, have relatively low cultural knowledge. Cultural competency is defined as an ability to recognize, to acknowledge and connect with persons from cultures other than one's own (Segen, 2011). Cultural competency is an essential component in educational standards for nursing students (AACN, 2008). While cultural competence has always been valued, its emphasis has increased. The cultural scales in the United States have shifted, awakening healthcare professionals to see the diversity that abounds. As health care professionals are introduced to different cultures, traditional views are challenged. Slowly healthcare must move from cultural blindness (a one-size fits all approach to health care) toward cultural competency (Cross et al, 1989). There is an expanding wisdom that a viable on ramp to the evolution of cultural competency is the ability of individuals to nurture their own cultural humility.

Schuessler, Wilder, and Byrd (2012) have defined cultural humility as the ability to see that one's own culture is not the only one. According to Hook, Davis, Owen, Worthington and Utsey (2013), it is the ability to be other-oriented. Fisher-Borne, Cain and Martin (2015) defined cultural humility as a process of developing the ability of being open to learning from others. This type of humility comes from learning to be comfortable with the admission one does not understand another's practices and beliefs while also being willing to learn about and value that culture from its members.

Campinha-Bacote (2019) presents a blending of cultural competence and cultural humility. He describes this synergistic relationship as a holistic view, where the relationship becomes greater than the effects that each one alone can produce. Campinha-Bacote (2019) uses the term cultural competemility to blend cultural competency (compete) and cultural humility (mility). This creates a process of being along with becoming. This lends support to defining cultural competence as knowledge and cultural humility as a process of self-reflection (Tervalon \& Murray-Garcia, 1998). This paves the way to use immersion study abroad as a learning technique that has a focus using reflective journaling to begin developing cultural humility. 
In 2018 and 2019, this author led four groups of undergraduate baccalaureate nursing students in ten-day immersion trips to Mexico to begin the process of developing cultural humility. While the focus of these trips was on Mexican culture, the concepts are transferable to other cultures around the world. Campinha-Barcote (2019) sees reflection as an essential part of cultural humility, and a process leading to knowledge of a culture through engaging encounters, becoming aware of one's own biases and "isms" (e.g. ethnocentrism, ageism, classism, racism, etc.)

\section{Method}

There are many modalities for fostering cultural competency; there is no consensus on best practices. Cultural Immersion via short-term study abroad is one method used to develop cultural competency and cultural humility in undergraduate students. This method is ideal for students who have limited time and financial resources. This method also creates a place for students to work on metacognition, the what, how and why of what they are learning (Billings and Halstead (2016). These authors identify metacognition as essential for the college level study. The purpose of this paper is to describe how a short-term study abroad trip can develop cultural humility and support cultural competency. Foronda, Baptiste, Reinholdt and Ousman's (2016) model for developing cultural humility was used to guide this study abroad's learning activities. This ten-day cultural immersion was based in Cuernavaca, Morales, Mexico in partnership with Cemanahuac Educational Community. This collaboration provided students with cultural and language immersion in Hispanic culture and health. While in Mexico, students had the opportunity to develop and practice skills in communication, collaboration, leadership while learning about the culture of Mexico. The language portion of the immersion was focused on healthcare.

Short-term study abroad is considered a high impact practice for student engagement. This engagement helps in development of dispositional learning such as expression, critical thinking, growth mindset, resilience, and self-regulation of behavior (Kuh, et al, 2018). It also promotes cultural competency which has been identified by the American Association of Colleges of Nursing (AACN; 2008) as a key component of baccalaureate nursing education. As the population in the United States is growing more diverse, so cultural competency must grow proportionally (Byrne, 2016). Immersion experiences can lead to the development of culturally competent nurses. Nurse educators are charged with developing cultural competency in students. AANC has identified five competencies that provide a framework and strategies to provide nursing students with the basics of providing culturally competent care. These competencies are based on the need to develop worldviews, acknowledge and eliminate health disparities, develop cross-cultural communication, and accept the need for lifelong learning assure culturally competent health care. These competencies help to provide for improved health outcomes (AACN, 2008).

Quantifying or capturing outcomes of an immersion study abroad is elusive. Kuh, et al. (2018) suggested that reflective writing increases awareness and helps students to connect experiences and develop meaning to them. While students are taught the concept of cultural competency in the classroom pre-trip, the practice of reflective writing facilitates moving from knowledge of culture to the area of developing a posture of cultural humility. During this trip, daily journaling, reflective writing assignments and daily debriefing sessions were used. The goal was for these strategies for self-evaluation and awareness to promote the understanding cultural competency in ways that cannot be taught in a traditional classroom setting (Schuessler, Wilder, \& Byrd, 2012).

Developing cultural humility can also be an elusive process as it involves challenging the individual to be introspective, a highly subjective process. According to Hook, Davis, Owen, Worthington and Utsey (2013), it is an ability to be other-oriented. Cultural humility is integral to becoming culturally competent. Tervalon and Murray-Garcia (1998) provided the seminal work on cultural competence and cultural humility. They noted that these two concepts are linked but can be distinguished from each other. Becoming culturally competent requires the development of cultural humility. Cultural humility becomes the action portion of cultural competency. It equips the healthcare professional to provide culturally appropriate, patient centered care and create an inclusive environment. In a concept analysis of cultural humility, Foronda, Reinholdt and Ousman (2016) identified that the act of practicing cultural humility goes hand in hand with forming an affinity for lifelong learning. Tervalon and Murray Garcia, go on to identify three factors were identified as important in developing cultural humility. These are a lifelong commitment to self-evaluation and self-critique; fixing power imbalances, and developing partnerships with people and groups who advocate for others. These authors were the first to describe power imbalance as a negative outcome when cultural humility is not achieved.

Traditional teaching methods may raise awareness of the need for cultural humility, but such internal culture change requires mechanisms that promote a reincarnation of self to level the playing field when approaching others. Schuessler et al., (2012) identify methods that incorporate reflection on experiences can increase a 
students' awareness of their cultural competence and increase cultural humility. Foronda et al. (2016) also describe strategies to best accomplish cultural humility and promote a changing perspective and self-awareness. Five of their strategies were employed in the students' trip to Mexico. These are openness, self-awareness, becoming egoless, supportive interaction, self-reflection, and critique. Openness is described as a willingness to investigate new ideas. Self-awareness is defined as knowing one's strengths, values, beliefs and behaviors in the manner that others see one. Becoming egoless means being humble and developing respectfulness in all one does. Supportive interaction occurs as the result of positive engagement with others. Finally, self-reflection and critique include the process of reviewing one's own thoughts, feelings, and actions (Foronda, et al., 2016). These five concepts identified as building cultural competency were used on the student experience in Mexico. In this trip, the goal was to immerse students into a new culture.

\section{The Study Abroad Experience}

The short-term study abroad trip for undergraduate students was planned with Cemanahuac Educational Community in Cuernavaca, Morales, Mexico. The students had all experienced U.S. healthcare, but had not been exposed to ideas from other countries' medical systems. The focus of the trip was to increase awareness and learning of Hispanic culture, healthcare, and quality of life. Students lived with host families for the duration of the trip. Meals were taken with host families but also included experiences in restaurants, stores, and other businesses. The students also took a course in Spanish for healthcare workers taught by native Spanish speakers for a total of sixteen hours during the trip. Excursions to Aztec and Mayan ruins were included to expose students to the history and evolution of Mesoamericans. Throughout their stay, the students visited various health care settings, and spent time with a curandero (traditional healer). While students started the trip with an understanding of the definition of cultural competency and cultural humility, it was only in Mexico that they began to develop an understanding of the importance of Hispanic cultural competency and that understanding improves health outcomes. For example, students participated in a traditional Aztec Steam bath, which is used for purification and improving overall health. A variety of herbs and chamomile are used in the steam bath to treat a variety of ailments, including anxiety. This practice of traditional medicine in Mexico is still used and the students' gained an understanding of how these treatments are combined with more modern methods of treatments, and not seen as "nontraditional " interventions as they are in the United States.

For example, students visited the Ethnobotanical Garden which houses the National Collection of Medicinal Plants. Registered healers can use this garden as a source of the plants and herbs used in their practice. The plants in this garden are referenced in the Badianus Manuscript from 1552. It was written by an Aztec physician and translated into Latin by an Aztec Indian. This manuscript shows no traces of European influence. It was this experience that gave the students an understanding of disease treatment from herbal medicines and other modalities such as herbs, bark, teas, plants, massages and steam baths, without looking to a surgical treatment (World Research Foundation, n.d.). On the drive from Mexico City to Cuernavaca students viewed the emblem of the National Institute of Cardiology in Mexico. This emblem brought the bridging between the old and new into bold relief. This Institute does leading research in cardiology for the world. Yet its emblem, designed by the famous muralist Diego Rivera, uses a drawing from the 1552 Banianus Manuscript. It depicts the Mexican heart flower (Yoloxochitl) which has mild digitalis-like properties (Davies \& Hollman, 1999.).

Understanding how other countries conceptualize and deliver health care is an important outcome of study abroad experiences. For example the healthcare system in Mexico highlights a different method of healthcare economics (affordable care to all), and creates an understanding of Mexican culture that provides a perspective for students when caring for patients in the United States who are of Mexican origin. To gain a deeper understanding of how Mexico addresses health promotion, students spent time with pharmacists, public health nurses and other health care professionals. They assisted with a mobile immunization clinic that traveled to areas in the city that were highly populated. These clinics are held in areas where families are present in large numbers such as churches on baptism days, waiting areas for public services and high-volume shopping areas such as big box stores. Taking needed vaccinations to adults and children where they gather for daily tasks increases the number of individuals receiving their immunizations. This provides an efficient and effective method to reach vulnerable populations such as children, pregnant women, and older adults.

Other public health initiatives that students witnessed were such things as the practice of removing salt from restaurant tables (one must ask the wait staff for salt) because in Mexico, hypertension is one of the leading chronic health conditions (Barquera et al, 2010). Barquera et al also cite diabetes and high cholesterol levels as other common chronic health conditions in Mexico. To help address such health conditions, the Paseo de la Reforma (the main street in Mexico City) is closed to automobile traffic on Sundays to promote bicycle riding and walking for bicycle riding and walking. Areas for young children are provided so that adults can participate 
in the free yoga, Zumba and other activities are offered in parks along the way. Bicycles are even free for use during early hours (Feather and the wind, 2018). Students were surprised by the large numbers of individuals and families who participated in these events and were able to observe the open, friendly atmosphere.

\section{Results}

Each day ended with a time for debriefing of the day's events. Evening debriefing also supports peer learning (Billings \& Halstead, 2016, pp. 248-259). This experience incorporated the strategies to increase cultural humility identified earlier by Tervalon and Murray Garcia (1998). For example, students were encouraged to consider on how they worked being open to their experiences, to respect cultural differences, and to reflect on their learning. These sessions lasted about one hour. The group used Socratic questioning to start discussions with themes around the day's events. For example, students might be asked, "What did you see today that you didn't expect?" "Does this happen in your hometown?" This allows students to transfer facts from one context to another and stimulate metacognitive thinking. When topics emerged that the group did not understand or know about, small groups of students were formed to be teams, with the expectation to share the new information with the group at the next meeting.

Reflective practices are supported in Fononda et al. (2016) model of cultural humility. Bain's (2004) study of best practices for getting students to talk were employed. The exchange of ideas was encouraged to facilitate thinking and learning and support the openness competency. To accomplish this, students were asked to prepare for the group by collecting their thoughts from the day in a short writing in their journal. Then, faculty used exploratory questions to stimulate sharing and start the discussion. This was then moved to building interpretations and solutions through open-ended questions which helped to move the student toward the competencies of self-awareness and egolessness. These evening discussion groups also help to build supportive interaction within the group (Bain, 2004, pp. 126-134). While the pre-trip meetings were constructed to build trust among the students and the faculty; it was the rapport among the group members and the immersion into a foreign culture that continued to build trust and open interaction. During this process the faculty took into account that some students may be shy or reluctant to speak out in-group settings. Those students were engaged one on one basis to establish ways to help them feel more comfortable and able to contribute during group times.

During the immersion trip, students were taught what it meant to become lifelong learners. As part of continuous learning, students were taught the importance of self-evaluation, and through the practice of daily reflective journaling. Power imbalances, discussed by Foronda, et al. (2016) as being in opposition to diversity, are explored in current event lectures and as they are observed while in the community during the immersion experience.

An essential component to this experience is the partnership built with the organization acting as a liaison with the host country and the educational institution. Cemanahuac Educational Community has a long history of advocating for others throughout their local community as well in the country of Mexico. This alliance has been formed and strengthened over a two-year period and now has a firm foundation for further work going forward.

\section{Conclusion}

On return from the trip, students were asked to write a reflection on new awareness or insights about Hispanic cultural humility they experienced.

Students shared:

"Opened my mind to realize that there are many ways to enjoy where you are in your life; and "....allowed me to connect on a deeper level with my host family who treated me like I was their own."

"I was afraid of feeling isolated and lonely during the host family stay. I was wrong, I became a part of everyday family life and learned a new perspective on ways to live."

These comments indicate growth around cultural humility. Other comments indicated an increase in cultural competency.

"Without understanding a person's culture, I can't provide the best care that they may be in need of."

"During this trip I became aware of how much health and wellness I can help others with while learning about their culture and values surrounding health."

"I realize we all share struggles of feeling judged, it's not just me."

For this group of students, it became evident that through the reflective writings and daily debriefing, cultural humility began to emerge, students embraced this as a way of learning, and their perspective began to change. 
Going forward students will provide feedback six months and twelve months post trip in order to identify new insights have developed or if they have had the opportunity to use their new found cultural knowledge of competency and humility in that way.

Planning for the next immersion study abroad trip has begun. Reflective journaling techniques will be explained during one of the pre-trip sessions. This will help students understand the expectations of daily journaling and the rationale for using it. Collection of student writings will begin to facilitate a descriptive review for themes that emerge. A follow up post-trip will occur at six and twelve months to survey the students to see if they have new insights or had the opportunity to use their newfound cultural knowledge of competency and humility. This follow up is supported in Foronda et al's model (2016).

Further study and review of immersion trips need to continue to validate Foronda's model of cultural humility. Further development of Hook (2013) scale of cultural humility needs to continue with the inclusion of Campinha-Barcote's cultural competemility. This will help to develop more knowledge and methods of infusing cultural competence and cultural humility in students to prepare them for professional work in today's global culture.

\section{References}

American Association of Colleges of Nursing. (2008). Cultural Competency in Baccalaureate Nursing Education. Washington, D. C.

American Association of Colleges of Nursing. (2008). Tool kit of resources for Cultural Competent Education for Baccalaureate Nurses. Washington, D. C.

Bain, K. (2004). What the best college teachers do. Harvard University Press, Cambridge.

Barquera, S., Campos-Nonato, I., Hernández-Barrera, L., Villalpando, S., Rodríguez-Gilabert, C., Durazo-Arvizú, R., \& Aguilar-Salinas, C. A. (2010). Hypertension in Mexican adults: results from the National Health and Nutrition Survey 2006. Salud Publica Mex, 52(1), S63-S71.

Billings, D. M., \& Halstead, J. A. (2016). Teaching in Nursing A guide for faculty (5th ed.). St. Louis.

Bond, L. L., Kardong-Edgren, S., \& Jones, M. E. (2001). Assessment of Professional Nursing Students' knowledge and attitudes about patients of diverse cultures. Journal of Professional Nursing, 17(6), 305-312.

Byrne, D. (2016). Cultural competency in baccalaureate nursing education: a conceptual analysis. International Journal of Human Caring, 20(2), 114-119.

Cai, W., \& Sankaran, G. (2015). Promoting critical thinking through an interdisciplinary study abroad program. Journal of International Students, 5(1), 38-49.

Campinha-Barcote, J. (2019). Cultural competemility: A paradigm shift in the cultural competence versus cultural humility debate-part 1. Online Journal of Issues in Nursing, 24(1), 4-14. https://doi.org/10.3912/OJIN.Vol24No01PPT20

Cross, T. L., et al.. (1989). Towards a Culturally Competent System of Care: A Monograph on Effective Services for Minority Children Who Are Severely Emotionally Disturbed. Georgetown University Child Development Center, Washington, D. C.

Davies, M. K., \& Hollman, A. (1999). Instituto Nacinal de Cardiologia Ignacio Chavez. Heart, 81, 110.

Feather and the Wind. (2018, December 15). How to enjoy a free Sunday morning bike ride in Mexico City [Blog post]. Retrieved from https://www.featherandthewind.com/blog/mexico-city-sunday-bike-ride

Fisher-Borne, M., Cain, J. M., \& Martin, S. L. (2015). From mastery to accountability: Cultural humility as an alternative to cultural competence. Social Work Education, 34, 165-181. https://doi.org/10.1080/02615479.2014.977244

Foronda, C., Baptiste, D. L., Reinholdt, M. M., \& Ousman, K. (2016). Cultural Humility: A concept analysis. Journal of Transcultural Nursing, 27(3), 210-217.

Hook, J. N., Davis, D. E., Owen, J., Worthington, Jr. E. L., \& Utsey, S. O. (2013). Cultural humility: Measuring openness to culturally diverse clients. Journal of Counseling Psychology, 60(3), 353-366.

Isaacson, M. (2014). Clarifying Concepts: Cultural Humility or Competency. Journal of Professional Nursing, 30(3), 251-258.

Kuh, G. D., Gambino, L. M., Bresciani-Ludvik, M., \& O’Donnell, K. (2018). Accentuating dispositional learning from HIPs using ePortfolio. Assessment Update, 30(3), 8-9. 
Mills, L. H., Vrba, T., \& Deviney, D. (2012). Enriching the short-term study abroad program: A case study. Retrieved from http://asbbs.org/files/ASBBS2012V1/PDF/M/MillsL.pdf

Schuessler, J. B., Wilder, B., \& Byrd, L. W. (2012). Reflecting journaling and development of cultural humility in students. Nursing Education Perspectives, 33, 96-99.

Segen's Medical Dictionary. (2011). Retrieved June 20, 2019, from https://medical-dictionary.thefreedictionary.com/cultural+competence

Sousa, P., \& Almeida, J. L. (2016). Culturally sensitive social work: Promoting cultural competence. European Journal of Social Work, 19, 537-555. https://doi.org/10.1080/13691457. 2015.1126559

Streets, B. F., Wolford, K., \& Guerda, N. (2015). A culturally competent immersion protocol, Petit Goave, Haiti. International Research and Review: Journal of Phi Beta Delta Honor Society for International Scholars, $5(1), 1-24$.

Taliaferro, D., \& Diesel, H. (2016). Cultural Impact with Reflective Journaling. International Journal for Human Caring, 20(3), 155-159.

Tervalon, M., \& Murray-Garcia, J. (1998). Cultural humility versus cultural competence: a critical distinction in defining physician training outcomes in multicultural education. Journal of Health Care for the Poor and Underserved, 9(2), 117-125.

World Research $\quad$ Foundation. $\quad$ (n.d.). Retrieved from http://www.wrf.org/ancient-medicine/badianus-manuscript-americas-earliest-medical-book.php

\section{Copyrights}

Copyright for this article is retained by the author(s), with first publication rights granted to the journal.

This is an open-access article distributed under the terms and conditions of the Creative Commons Attribution license (http://creativecommons.org/licenses/by/4.0/). 